\title{
Influence of permafrost thaw on redox, iron speciation, and bioavailable phosphorus in a subarctic peatland
}

\author{
M.R. Barczok ${ }^{1 *}$, C.E. Smith ${ }^{2}$, L.E. Kinsman-Costello²,
}

D.M. Singer ${ }^{1}$, E.M. Herndon ${ }^{3}$

${ }^{1}$ Department of Geology, Kent State University, Kent, OH 44242 ,

USA (*correspondence: mbarczok@kent.edu)

${ }^{2}$ Department of Biological Sciences, Kent State University, Kent, OH 44242, USA

${ }^{3}$ Environmental Sciences Division, Oak Ridge National

Laboratory, Oak Ridge, TN 37830, USA

Increasing temperatures in the arctic can cause permafrost thaw and radically change hydrological and redox conditions in the soil. Changes in redox conditions can cause the precipitation and dissolution of redox sensitive minerals like iron (oxyhydr)oxides (henceforth called $\mathrm{Fe}$ oxides). $\mathrm{Fe}$ oxides have a high capacity to adsorb phosphate $\left(\mathrm{PO}_{4}{ }^{3-}\right)$ a limiting nutrient in many arctic and subarctic environments. Consequently, $\mathrm{Fe}$ oxides may play an important role in controlling the bioavailability of phosphorus $(\mathrm{P})$ in soils.

To explore these complex interactions between permafrost thaw, $\mathrm{Fe}$ oxides, redox conditions, and $\mathrm{P}$ bioavailability, we conducted an in situ incubation experiment along a permafrost gradient in a subarctic peatland in Abisko, Sweden. The permafrost gradient included an elevated palsa with permafrost close to the soil surface, a collapsed bog with deep permafrost and surface ponding, and a fen with no permafrost and surface ponding. Soil redox conditions were measured continuously for over a month in the palsa, bog, and fen. Mesh bags, filled with local iron-rich sediments comprised of ferrihydrite, organic-bound $\mathrm{Fe}$, and goethite and with either $\mathrm{P}$ addition or none, were buried under the topsoil at each site and incubated for one or eight weeks. Incubated materials were subsequently analyzed with $\mathrm{x}$-ray absorption fine structure (XAFS) spectroscopy to evaluate changes in iron speciation and with sequential extractions to quantify changes in total $\mathrm{Fe}$ and $\mathrm{P}$.

Redox conditions transitioned from oxic to anoxic as permafrost thaw increased and caused surface ponding, although redox was variable across the thaw season. The proportion of total $\mathrm{Fe}$ present as ferrihydrite, a poorly crystalline Fe oxide, increased in sediments incubated in the bog and fen while remaining unchanged in the palsa. In contrast, $\mathrm{Fe}$ incubated in the palsa remained primarily bound to organic matter. We conclude that fluctuating redox conditions in the bog and fen topsoils facilitated precipitation of new ferrihydrite in the incubated material. Increases in ferrihydrite could decrease bioavailable phosphate in the topsoils and potentially limit plant growth and microbial activity. 